\title{
Effect of MgFeSi Inoculant on Properties of Cast 6061 Al Alloy for Brake Master Piston Application
}

\author{
Olawale Olarewaju Ajibola ${ }^{1,2}$ and Daniel Toyin Oloruntoba ${ }^{1}$ \\ ${ }^{1}$ Metallurgical and Materials Engineering Department, Federal University of Technology Akure, Akure 340252, Nigeria \\ ${ }^{2}$ Materials and Metallurgical Engineering Department, Federal University Oye Ekiti, Oye Ekiti 371104, Nigeria \\ Correspondence should be addressed to Olawale Olarewaju Ajibola; olawale.ajibola@fuoye.edu.ng
}

Received 13 May 2015; Revised 2 September 2015; Accepted 15 September 2015

Academic Editor: Kwo Young

Copyright (C) 2015 O. O. Ajibola and D. T. Oloruntoba. This is an open access article distributed under the Creative Commons Attribution License, which permits unrestricted use, distribution, and reproduction in any medium, provided the original work is properly cited.

\begin{abstract}
The influence of varying amount of MgFeSi inoculant on properties of cast $6061 \mathrm{Al}$ alloy for brake master piston application has been studied and reported in this paper. Cast samples were produced at three pouring temperatures $\left(700,750\right.$, and $\left.800^{\circ} \mathrm{C}\right)$ with $\mathrm{MgFeSi}$ varied from 1 to $3 \%$. Wear resistance tests were performed on cast alloy in brake oil. Wear resistance tests results were validated by nondestructive examinations using photomicroscopy, SEM, EDX, and XRD data. The addition of MgFeSi influenced both the mechanical (hardness, strength, and wear resistance) and metallurgical properties (microstructures) of the cast alloy. Al grains were more refined and yielded good strength properties. Inoculating the melt with MgFeSi forms insoluble compound particles and is responsible for grain refinement. The increased amount of $\mathrm{MgFeSi}$ from 1 to 3\% improved the wear resistance of the cast piston under lubricating condition using brake oil.
\end{abstract}

\section{Introduction}

The application and acceptability of sand casting are an important aspect of foundry/casting practices ranging from the numerous cottage and large-scale manufacturing industries [1]. Small and large engineering components (machine parts) are made from different metals and alloys such as steel, cast iron, copper, bronze, brass, and many other known aluminium alloys. The right practice of casting starts with the understanding the control and chemistry of the melt. Casting aluminium alloy entails proper handling of materials: type of furnace, fuel, the melting pot, the selection of fluxing additives, alloying elements, and the moulding sand composition. Superior properties can be achieved in aluminium alloys through systematic control of casting processes.

Literature is scarcely available on the MgFeSi inoculation of $\mathrm{Al}$ alloys, but some latest progress on reports of inoculants in alloy and casting similar to $\mathrm{MgFeSi}$ in $\mathrm{Al}$ alloys. These include inoculation treatment of ductile iron [2], cast iron [3], oxide particles inoculant in $\mathrm{Al}$ alloys [4], and pure aluminium inoculation treatment with titanium and boron [5-8]. The current study reports the effect of MgFeSi inoculation as a means of grain refinement and enhancing the mechanical properties (strength, hardness, etc.) of $\mathrm{Al}$ alloys.

The mechanical strength, hardness, and the microstructure of the aluminium cast could be improved by controlled melting, pouring temperature, and the solidification processes and proper management of other different controlling factors [9-12]. The pouring temperature for aluminium alloys usually ranges from 720 to $790^{\circ} \mathrm{C}$, even though thin-section cast products can be poured at temperatures as high as $845^{\circ} \mathrm{C}$ as found in the literature [8].

The moulding sand permeability influences the cast product quality. The pouring temperature, solidification, and cooling rate are tailored to control the microstructure of the cast aluminium alloy. This influences the piston making [13, 14] and it also affects the hardness of the cast alloy. This is in agreement with other researchers $[10,15]$. The hypereutectic aluminium alloys (390, B390, and 393) are used primarily for wear applications (engine blocks, compressors, pistons, pumps, pulleys, brake systems, etc.). They are also used for thin parts since they have exceptional fluidity $[9,16]$. 
In this work, the Al-Si alloys are produced by sand casting. This technique is identified as a relevant method for the production of many aluminium alloy parts with outstanding metallurgical properties suitable for the desired level of application. In designing a right alloy for the production of cast piston, each of the alloying elements plays a significant role. It has considerable influence on the properties of the cast piston. For purposes of understanding the effects and importance of alloying elements, the alloying elements contained in the as-received piston are classified into three as major, minor, microstructure modifiers or impurities. Conversely, the impurity elements in some alloys might be major elements in others. The major alloying elements typically identified in scrap aluminium alloys are silicon $(\mathrm{Si})$, magnesium $(\mathrm{Mg})$, and copper $(\mathrm{Cu})$. In general, the microstructure modifying elements are titanium (Ti), manganese (Mn), and chromium (Cr). The impurity elements are iron $(\mathrm{Fe})$, chromium $(\mathrm{Cr})$, and zinc $(\mathrm{Zn})$ [9]. The copper in alloy imparts good strength and hardness, making it heat treatable, and possesses enhanced machinability.

The only deliberate and guarded additions of zinc $(\mathrm{Zn})$ to aluminium casting alloys are in the 7XXX series. It happened just as an acceptable impurity element in many secondary (scrap-based) casting alloys. It is quite neutral; it neither adds nor subtracts alloys properties. Zinc is a dense (heavy) element, and it increases the alloys mass density [9]. The behaviour of Al-Si alloy can be explained using Al-Si phase diagram. In the present study, the amount of Si ranged from 0.7 to 1.3 approximate values from the as-received scrap to the cast $\mathrm{Al}$ with inoculant as in Figure 1.

The equilibrium phases diagram for the binary $\mathrm{Al}-\mathrm{Si}$ system is shown in Figure 1. Hypoeutectic alloys are alloys having silicon content less than the eutectic composition. Many common hypoeutectic alloys fall between 5\% and 10\% silicon. It is conventional that the eutectic reaction occurs with $12.6 \%$ silicon at $577^{\circ} \mathrm{C}$ temperature [17]. A substantial quantity of $\mathrm{Si}$ dissolves in solid $\mathrm{Al}$ at higher temperatures. The maximum solubility is seen to be $1.6 \%$ at the eutectic temperature whereas only an insignificant quantity of $\mathrm{Al}$ dissolves in Si. Considering different phase diagrams for the $\mathrm{Al}-\mathrm{Si}$ system in various literature, there are discrepancies as to the exactness of the eutectic composition and, to a less significant extent, the eutectic temperature. This is because the Al-Si eutectic formation is very responsive to a small change in quantity of impurities, particularly $\mathrm{P}, \mathrm{Na}$ and other alkaline earth elements.

Eutectic alloys are formed between 10 and $13 \% \mathrm{Si}$ and consist principally of $\mathrm{Al}-\mathrm{Si}$ eutectic in the cast structure characterized by the following: a narrow range of freezing points, exceptional fluidity, high castability, and good wear resistance [13]. It is moderately ductile when being not alloyed and heat treatable to high strength property. When containing $\mathrm{Cu}, \mathrm{Mg}$, and occasionally $\mathrm{Ni}$, eutectic $\mathrm{Al}$ alloys are used extensively for pistons. Cast hypereutectic alloys are obtained between 15 and $20 \% \mathrm{Si}$. The cast structure is made of primary Si particles entrapped in Al-Si eutectic matrix. They have good high-temperature strength with remarkable wear resistance but low machinability. They are good for pistons, engine blocks, and compressor components $[13,14]$. FeSiMg

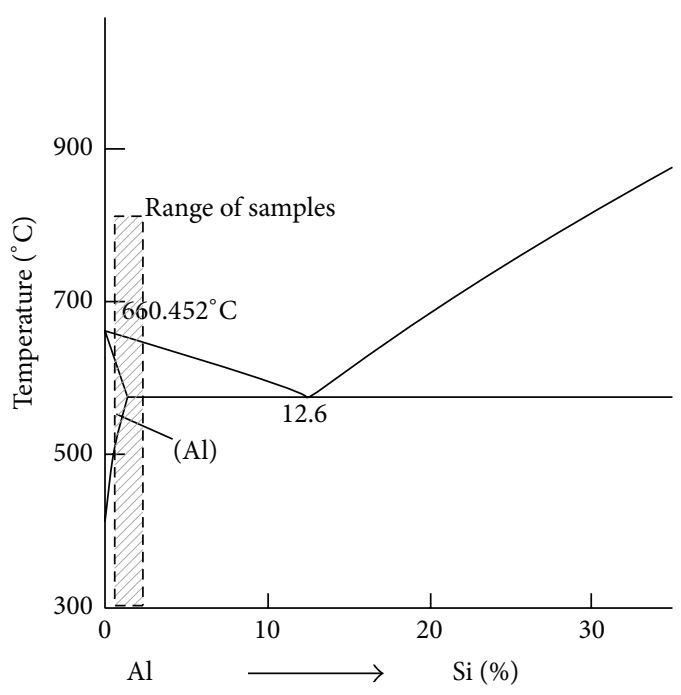

FIgURE 1: The aluminium-silicon phase diagram [17].

is widely used in the steelmaking and cast iron production and casting but literature is scarcely available (if any) on the use of FeSiMg in $\mathrm{Al}$ alloy casting. Thus, this is newly and briefly examined in the study. The hardness values and the mechanical strength are the only properties that are quantified in the study. Focus is given to the effect of the inoculant variation on the microstructure. Nevertheless, brief explanations were mentioned within the text. The authors had reported the mechanical properties of cast $\mathrm{Al}$ alloy in the previous study $[13,14]$.

\section{Materials and Method}

2.1. Production of Cast Aluminium Alloy Samples. Aluminium alloy scrap was obtained from the brake master piston. A branded FeSiMg7Rel with code name 7-1 was obtained from the chemical store. About $2 \mathrm{~kg}$ of the scrap was charged into the melting pot, fired, and melted using Taifa model electric furnace. The molten alloy was held for 10 minutes at three pouring temperature ranges between 750 and $800^{\circ} \mathrm{C}$ under a controlled atmosphere before pouring. Various quantities (1-3\%) of MgFeSi inoculant were used to treat molten $\mathrm{Al}$ metal. The procedure followed is similar to cast iron [3]. The moulding flasks were preheated before the casting process. The cast-aluminium-alloy samples were obtained at pouring temperatures of $750 \pm 10^{\circ} \mathrm{C}$. The molten metal was allowed to solidify and cool to obtain eutectic AlSi structured phase. The cast samples were removed from the sand mould, fettled, brush cleaned, and lightly machined on the lathe to get a rod of $300 \mathrm{~mm}$ length and $25 \mathrm{~mm}$ diameter. The cast (rod) was later cut to $2 \mathrm{~mm}$ thickness by $25 \mathrm{~mm}$ diameter for further processing.

\section{Experimental Details}

The hardness tests of $\mathrm{Al}$ alloy samples were determined using Brinell Hardness Tester. The microstructures of samples were 
TABLE 1: (a) AAS analyses of aluminium alloy samples. (b) Composition of the branded FeSiMg7Re1 powder.

(a)

\begin{tabular}{lccccccccc}
\hline Samples & $\mathrm{Al}$ & $\mathrm{Fe}$ & $\mathrm{Si}$ & $\mathrm{Mg}$ & $\mathrm{Cu}$ & $\mathrm{Zn}$ & $\mathrm{Ti}$ & $\mathrm{Mn}$ & $\mathrm{Cr}$ \\
\hline As-received Al scrap & 98.665 & 0.232 & 0.686 & 0.403 & 0.001 & 0.001 & 0.001 & 0.001 & 0.001 \\
Cast Al (no inoculant) & 98.44 & 0.163 & 0.327 & 0.294 & 0.01 & 0.001 & 0.001 & 0.001 & 0.001 \\
Cast Al (with inoculant) & 97.432 & 0.331 & 1.293 & 0.598 & 0.202 & 0.001 & 0.051 & 0.051 & 0.041 \\
\hline
\end{tabular}

(b)

\begin{tabular}{lcccccc}
\hline Brand tag & $\mathrm{Mg}$ & $\mathrm{Re}$ & $\mathrm{Si}$ & $\mathrm{Ca}$ & $\mathrm{Al}$ & $\mathrm{Fe}$ \\
\hline FeSiMg7Re1 & $6.0-8.0$ & $0.5-1.5$ & $38-44$ & $1.0-1.5$ & $<1.0$ & $44-53.5$ \\
\hline
\end{tabular}

examined by using a High-Resolution Metallurgical Microscope with the digital camera (Nikon-Eclipse M600 model). The sections were examined under different magnifications $(\times 10, \times 100, \times 200, \times 400$, and $\times 800)$.

The chemical composition of the cast samples was characterized by Atomic Absorption Spectroscopy (AAS-Thermo series 2000 model). The X-ray diffraction XRD (MiniDiffractometer MD-10 model with digital facilities) was used to determine grain sizes and possible phases. In addition, Scanning Electron Microscope with Energy Dispersive Xray facilities (Jeol JSM-7600F Field Emission SEM/EDX) was used to examine the microstructures at high magnifications.

The study evaluates the surface integrity of cast samples by wear tests with the view to assessing the performance of the cast piston specimens in brake fluid. The wear tests were performed on the as-received (AR) scrap pistons and cast piston samples (with and without varying amount of $\mathrm{MgFeSi}$ ) using a Wear Jig $[13,18,19]$. The samples are inserted into the Wear Jig and run for wear cycles range of 1225 to 122500 cycles varied at 1225 interval. The wear resistance is determined from wear volume (loss). The maximum volume loss $V_{w}$ of wear that can occur is described by [20] in Archard's equation:

$$
V_{w}=A d
$$

where $V_{w}$ is the volume of substance removed, $d$ is the distance slid, and $A$ is the cross-sectional area of the groove. Wear resistance $R$ is defined as the reciprocal of wear volume $V_{w}\left(\right.$ in $\mathrm{cm}^{-3}$ or $\left.\mathrm{mm}^{-3}\right)$ as in

$$
R=\frac{1}{V_{w}}
$$

The results of wear tests were used to interpret microstructural details, XRD, SEM/EDX, and AAS data generated from the research.

\section{Results and Discussion}

The chemical compositions of the as-received scrap alloy and the cast aluminium alloy samples used in this experiment are presented in Table 1(a).

Meanwhile the chemical composition of the branded FeSiMg7Rel powder used for the present work as given by the manufacturer is presented in Table $1(\mathrm{~b})$

The wear resistances (in oil) of cast aluminium alloy piston with and without $\mathrm{MgFeSi}$ additive are compared in

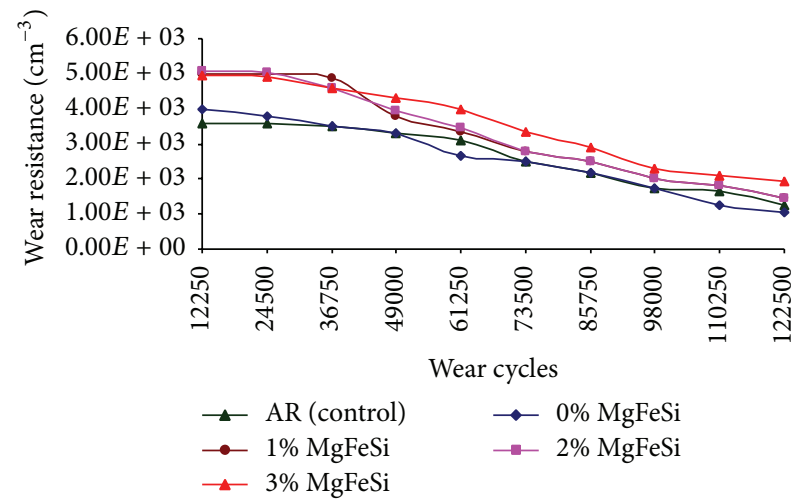

FIGURE 2: Result of wear resistance tests of as-received (AR) piston scrap and cast piston samples with varying percentage of MgFeSi in oil.

Figure 2. It is obvious that the addition of $\mathrm{MgFeSi}$ has a positive influence on all the alloys tested. Higher wear resistance performance was obtained from the present work using 3\% MgFeSi as compared with the results reported previously by Ajibola et al. [13, 14].

The wear resistance of all the $\mathrm{Al}$ alloy materials reduces with the increasing number of the wear cycles. The asreceived $\mathrm{Al}$ alloy wears at a very close trend of wear rate as the $1 \% \mathrm{MgFeSi}$ inoculated $\mathrm{Al}$ alloy. It is evident from the result (Figure 2) that there is increased wear resistance that results from the increased content of MgFeSi from $1 \%$ to $3 \%$.

\section{Microstructural Examination Scrap Sample and Cast Samples}

The surfaces and microstructures of scrap samples and cast samples studied using higher resolution metallurgical microscope with digital camera and SEM under different magnifications are shown in Figures 3-10(b). The EDX data are integrated into Table 2 for easy comparison. The table describes the composition of the grains of cast $\mathrm{Al}$ alloy (with and without inoculant) and the grain boundary (with inoculant).

The images in Figures 3(a)-3(c) show the surface appearances of the as-cast AA6061 Al alloy with varying percentage of $\mathrm{MgFeSi}$ observed at $\times 10$ magnification. For the reason of better clarity, Figures $4(\mathrm{a})-4(\mathrm{c})$ are the enlarged view of 


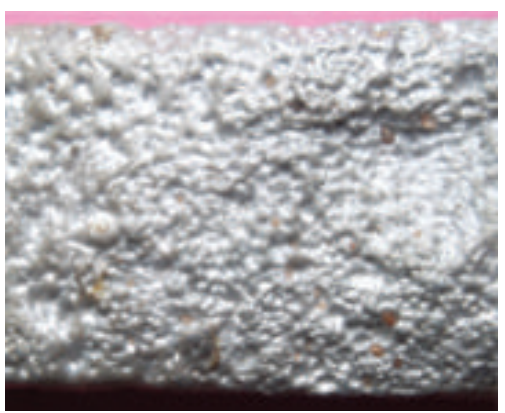

(a) $1 \% \mathrm{MgFeSi}$

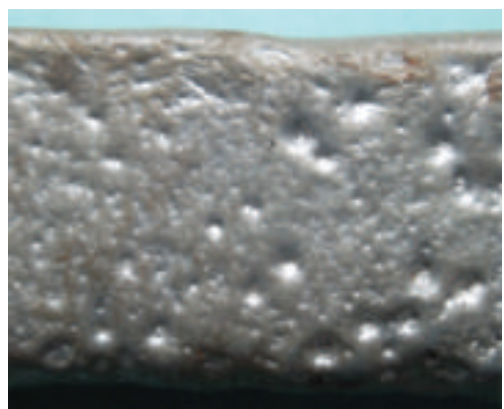

(b) $2 \% \mathrm{MgFeSi}$

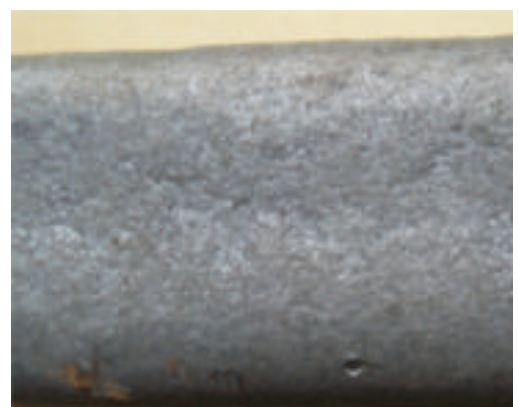

(c) $3 \% \mathrm{MgFeSi}$

Figure 3: Surfaces of as cast aluminium alloy with varying percentage of $\mathrm{MgFeSi}(\times 10)$.

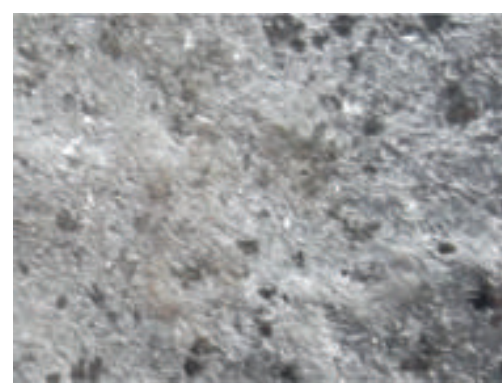

(a) $1 \% \mathrm{MgFeSi}$

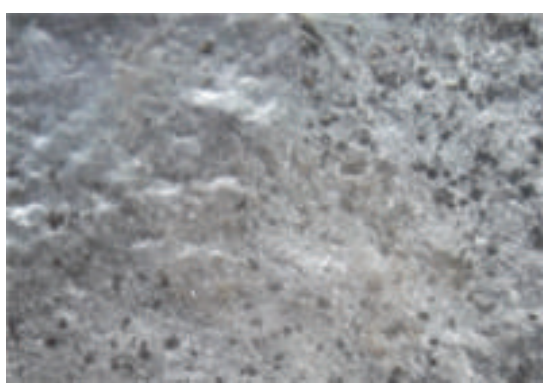

(b) $2 \% \mathrm{MgFeSi}$

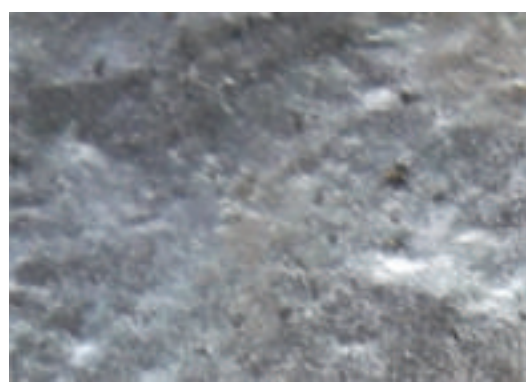

(c) $3 \% \mathrm{MgFeSi}$

FIGURE 4: Porosity of surfaces under microscopic camera $(\times 100)$.

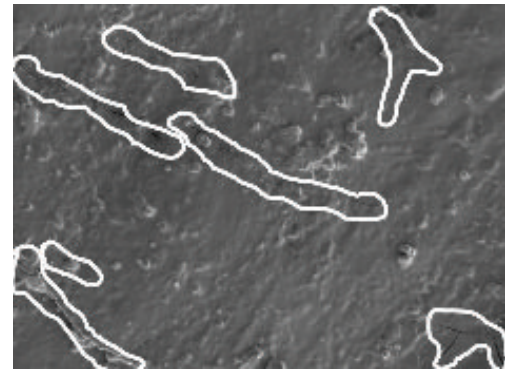

(a) $1 \% \mathrm{MgFeSi}$

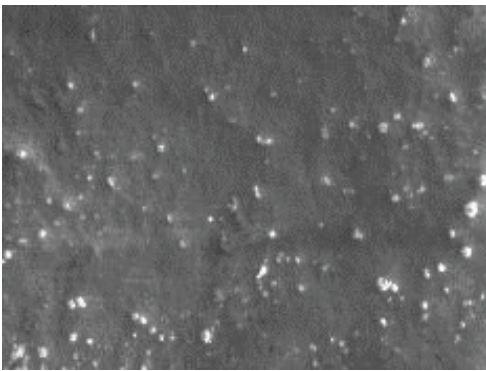

(b) $2 \% \mathrm{MgFeSi}$

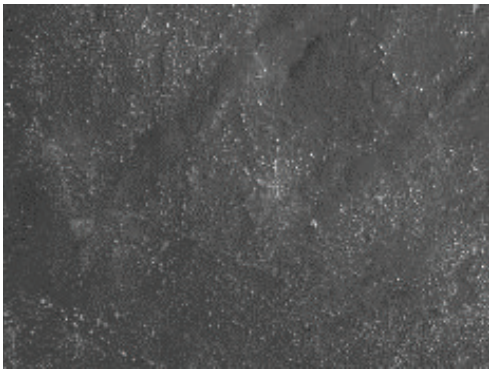

(c) $3 \% \mathrm{MgFeSi}$

FIGURE 5: (a) Cracks due to hot tearing; ((b)-(c)) topography and roughness of cast surfaces $(\times 1000)$.

TABLE 2: Composition of the grains and the grain boundary (with and without inoculant).

\begin{tabular}{|c|c|c|c|c|c|c|c|c|c|}
\hline Element (wt\%) & $\mathrm{C}$ & $\mathrm{O}$ & $\mathrm{Mg}$ & $\mathrm{Fe}$ & $\mathrm{Si}$ & $\mathrm{Zn}$ & $\mathrm{Cu}$ & $\mathrm{Al}$ & $\mathrm{Mn}$ \\
\hline Cast $\mathrm{Al}$ alloy grains (without inoculant) & 7.36 & 7.73 & 1.65 & 1.43 & 1.31 & 1.04 & 1.21 & 78.27 & - \\
\hline Cast $\mathrm{Al}$ alloy grains (with inoculant) & 4.15 & 3.75 & 2.36 & 3.51 & 2.25 & 1.85 & 2.86 & 78.11 & 1.16 \\
\hline Cast $\mathrm{Al}$ alloy grain boundary (with inoculant) & 6.55 & 8.08 & 2.43 & 4.27 & 3.39 & 1.71 & 1.34 & 72.23 & - \\
\hline
\end{tabular}

the same set of surfaces examined at $\times 100$ magnification. It could be observed that the cast surface appearance seems to improve with the increasing quantity of $\mathrm{MgFeSi}$. The pores in the cast are clearly revealed for each quantity of $\mathrm{MgFeSi}$ inoculant added. The $1 \% \mathrm{MgFeSi}$ cast product appears woolly with the combination of both large and fine pores. The SEM images in Figures 5(a)-5(c) show some other casting defects such as the cracks due to hot tearing and roughness of cast surfaces.

The chemical analysis shows that $98.665 \% \mathrm{Al}, 0.686 \%$ Si, $0.403 \% \mathrm{Mg}, 0.001 \% \mathrm{Cu}, 0.001 \% \mathrm{Zn}, 0.001 \% \mathrm{Ti}, 0.001 \%$ $\mathrm{Mn}, 0.001 \% \mathrm{Cr}$, and $0.232 \% \mathrm{Fe}$ are present in the scrap aluminium alloy. The identified trace elements or impurities are inevitably present in primary $\mathrm{Al}$ and consequently are 


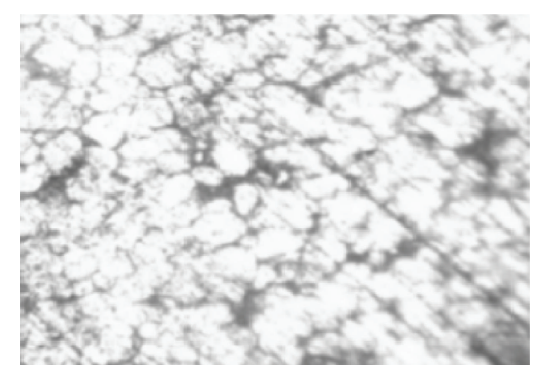

(a)

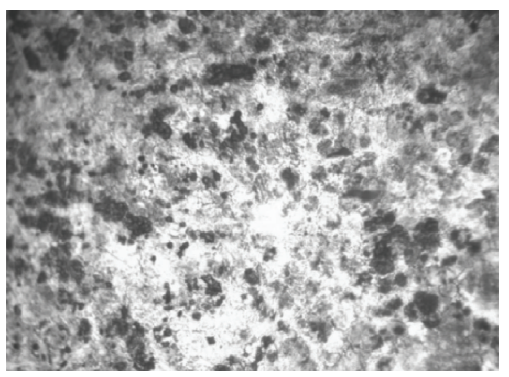

(d)

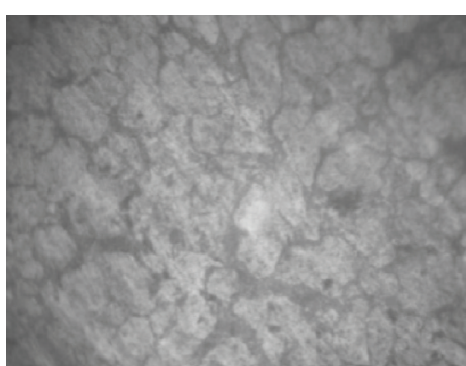

(b)

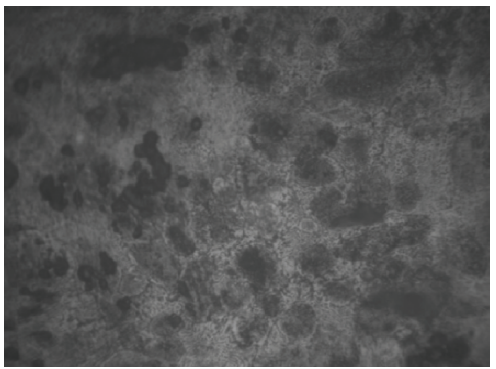

(e)

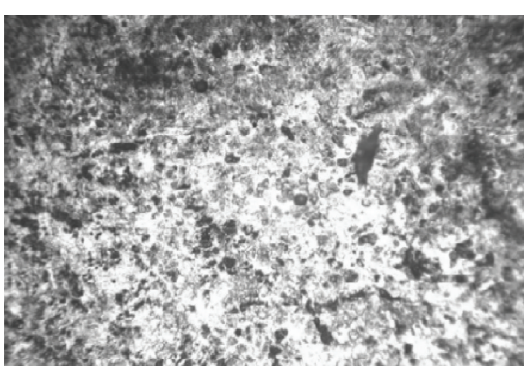

(c)

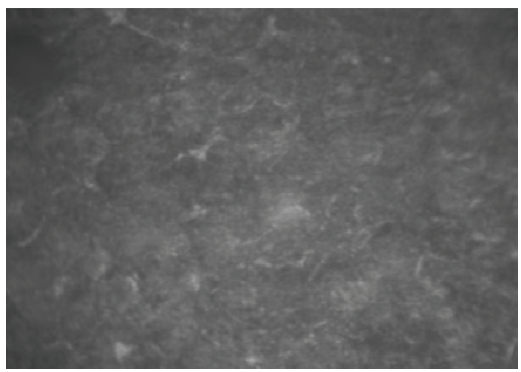

(f)

FIGURE 6: Microstructure of (a) as-received AR scrap Al alloy and cast piston with varying percentage of $\mathrm{MgFeSi}$ ((b) $0 \%$, (c) $1 \%$, (d) $2 \%$, (e) $3 \%$, and (f) $3 \%$ (iron-rich $\mathrm{Al}_{5} \mathrm{FeSi}$ phase)) poured at $750^{\circ} \mathrm{C}(\times 800)$.

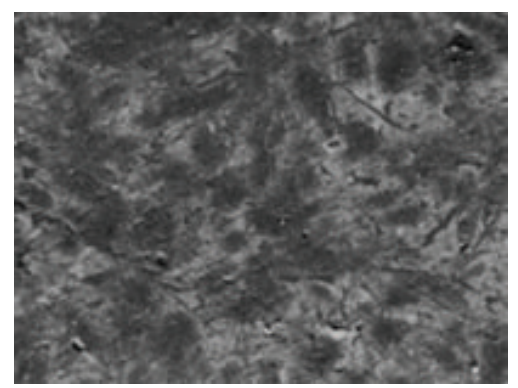

(a)

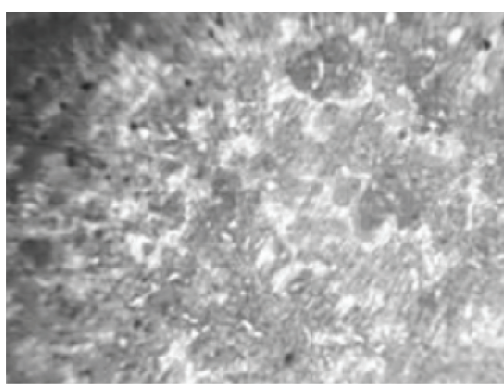

(b)

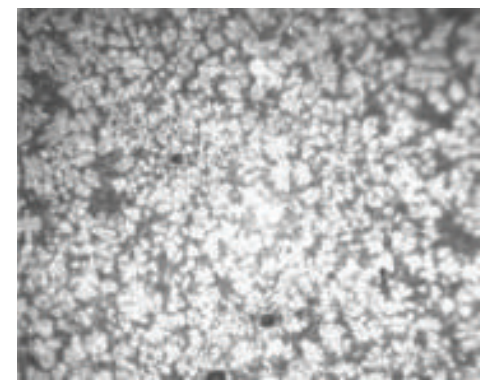

(c)

FIGURE 7: Microstructure of cast piston ((a), (b), and (c)) with nucleation of larger number of small grains with $3 \% \mathrm{MgFeSi}$ poured at $750^{\circ} \mathrm{C}$ $(\times 800, \times 400$, and $\times 200)$.

found downstream in wrought and foundry alloy products. The reduction in grain size is obtained by the nucleation of the aluminium phase that was achieved through $\mathrm{MgFeSi}$ inoculants used to provide the necessary nuclei. In the present study, the addition of $\mathrm{MgFeSi}$ initiated nucleation in collaboration with other factors like alloy composition, cooling rate, and the temperature gradient in the melt. With the addition of $\mathrm{MgFeSi}$ powder, $97.432 \% \mathrm{Al}, 1.293 \% \mathrm{Si}, 0.598 \%$ $\mathrm{Mg}, 0.202 \% \mathrm{Cu}, 0.001 \% \mathrm{Zn}, 0.051 \% \mathrm{Ti}, 0.051 \% \mathrm{Mn}, 0.041 \% \mathrm{Cr}$, and $0.331 \% \mathrm{Fe}$ were obtained in the cast piston. It is explained that there is increase in the \% Fe composition in the cast piston. This may be from both $\mathrm{MgFeSi}$ inoculation and/or the Fe pickup from the steel container (melting pot) due to higher solubility of $\mathrm{Fe}$ in molten $\mathrm{Al}$ [21].

The formation of $\mathrm{MgAl}_{2} \mathrm{O}_{4}$ and the $\mathrm{MgAl}_{2} \mathrm{O}_{4}$ particles is got from the addition of $0.49 \sim 0.70 \mathrm{wt} \% \mathrm{Mg}$ to pure $\mathrm{Al}$ [4]. But with the addition of $1-3 \% \mathrm{MgFeSi}$ to the melt, large amount of $\mathrm{Mg}$ is dissolved and forms compounds such as $\mathrm{MgO} \cdot \mathrm{Al}_{2} \mathrm{O}_{3}$ and $\mathrm{Al}_{2} \mathrm{CuMg}$ (Table 4). The MgFeSi supplies more $\mathrm{Mg}, \mathrm{Fe}$, and $\mathrm{Si}$ into the $\mathrm{Al}$ melt. Among all, silicon ( $\mathrm{Si}$ ) is the most noteworthy single alloying constituent in many of aluminium casting alloys. Silicon is primarily accountable for good castability, with no hot tearing or hot cracking defects as depicted in Figure 5(a).

Silicon plays a vital role as an alloying element manyfold. Figure 5 shows the influence of increasing $\mathrm{MgFeSi}$ content on the cast alloy property. In Figure 5(a), the cast alloy exhibited cracks, while microstructure details in Figures 5(b) and 5(c) are of better qualities. The white-marked areas in Figure 5(a) denote the traces of cracks due to hot tearing on the faces of cast $\mathrm{Al}$ alloy (without $\mathrm{MgFeSi}$ ) during solidification, though silicon has limited solid solubility (maximum 1.65\%) and can form a eutectic solution with aluminium at a significantly high level to $\sim 12.6 \%$ (Figure 1). MgFeSi inoculation imposed 


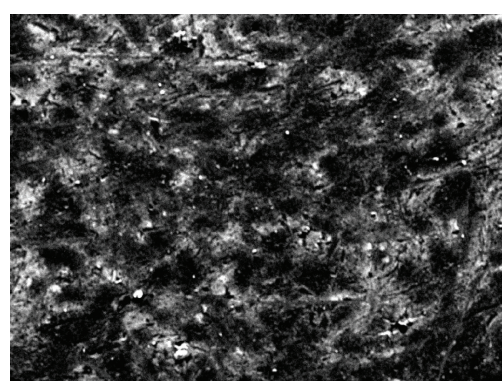

(a) $1 \% \operatorname{MgFeSi}\left(700^{\circ} \mathrm{C}\right)$

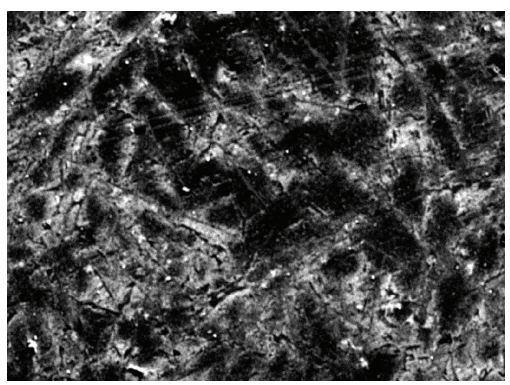

(d) $2 \% \mathrm{MgFeSi}\left(700^{\circ} \mathrm{C}\right)$

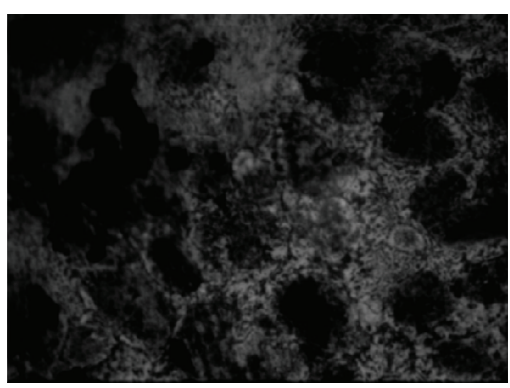

(g) $3 \% \mathrm{MgFeSi}\left(700^{\circ} \mathrm{C}\right)$

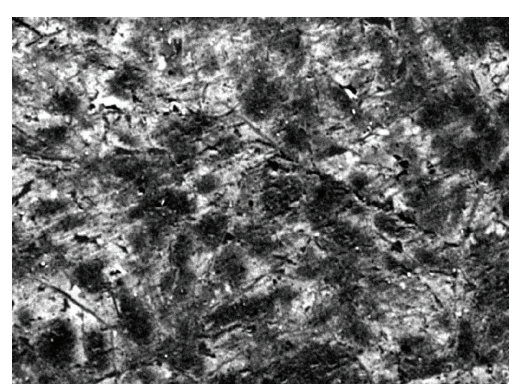

(b) $1 \% \operatorname{MgFeSi}\left(750^{\circ} \mathrm{C}\right)$

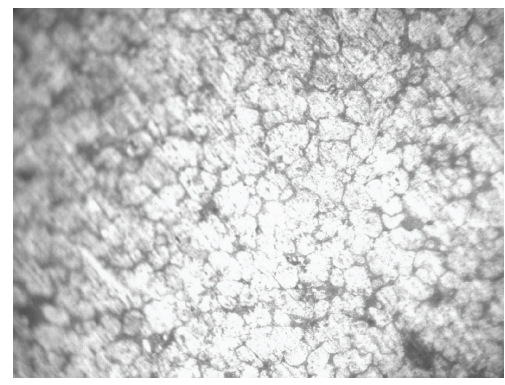

(e) $2 \% \mathrm{MgFeSi}\left(750^{\circ} \mathrm{C}\right)$

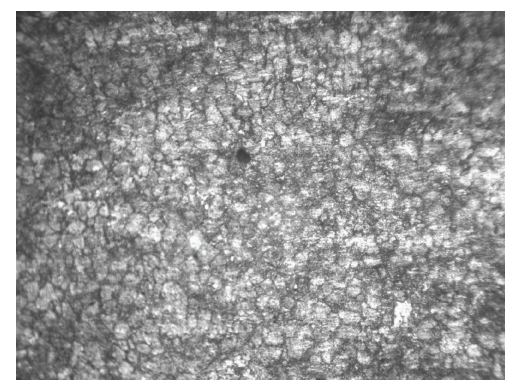

(h) $3 \% \mathrm{MgFeSi}\left(750^{\circ} \mathrm{C}\right)$

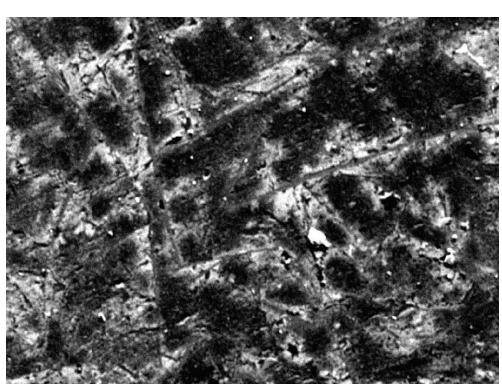

(c) $1 \% \operatorname{MgFeSi}\left(800^{\circ} \mathrm{C}\right)$

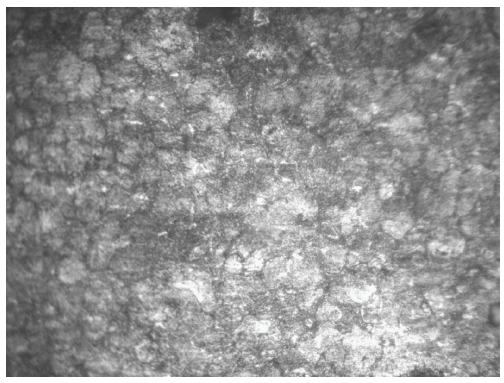

(f) $2 \% \mathrm{MgFeSi}\left(800^{\circ} \mathrm{C}\right)$

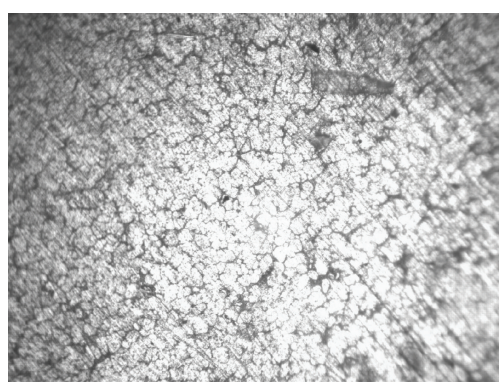

(i) $3 \% \operatorname{MgFeSi}\left(800^{\circ} \mathrm{C}\right)$

FIGURE 8: Effects of varying percentage of MgFeSi and casting temperatures on microstructure of cast piston $(\times 800)$.

TABLE 3: Effects of varying percentage of inoculant on mechanical properties of cast Al alloy samples.

\begin{tabular}{|c|c|c|c|c|c|c|c|c|}
\hline Sample & $\% \mathrm{MgFeSi}$ & $\begin{array}{l}\text { BHN } \\
\text { Pnt } 1\end{array}$ & $\begin{array}{l}\text { BHN } \\
\text { Pnt } 2\end{array}$ & $\begin{array}{l}\text { BHN } \\
\text { Pnt } 3\end{array}$ & $\begin{array}{l}\text { BHN } \\
\text { Pnt } 4\end{array}$ & $\begin{array}{c}\text { Average } \\
\text { BHN }\end{array}$ & $\begin{array}{c}\text { Strength } \\
(\mathrm{MPa})\end{array}$ & $\begin{array}{l}\text { Observation } \\
\text { (porosity, } \\
\text { etc.) }\end{array}$ \\
\hline Cast- 01 & 0 & 61.3 & 60.8 & 63.2 & 64.3 & 62.4 & 224.83 & Cracks, pores \\
\hline Cast-02 & 1 & 63.4 & 64.4 & 64.1 & 63.3 & 63.8 & 226.49 & More pores \\
\hline Cast-03 & 2 & 64.3 & 62.6 & 65.9 & 65.8 & 64.6 & 229.46 & Fewer pores \\
\hline Cast-04 & 3 & 61.4 & 71.2 & 69.4 & 60.8 & 65.7 & 237.14 & Few pores \\
\hline
\end{tabular}

more Si dissolution in the system and thus formed eutectic with aluminium to $\sim 2.25-3.39 \%$ in (Table 2). Silicon is a very hard phase that contributes significantly to aluminium alloy wear resistance $[13,14,22]$. It joins other elements to enhance the alloy mechanical strength (Table 3 ) and to make alloys heat treatable [23].

The presence of magnesium $(\mathrm{Mg})$ as alloying element strengthens and hardens aluminium castings (Table 3 ). The presence of $\mathrm{Mg}$ phase contained in the alloy was identified and diffracted as $\mathrm{Al}_{2} \mathrm{CuMg}$ and $\mathrm{MgO} \cdot \mathrm{Al}_{2} \mathrm{O}_{3}$ in the XRD analysis of the cast sample (Table 4). The combination of
Tables 3 and 4 may explain why the cast piston has high wear resistance compared to the as-received scrap piston sample (Figure 2).

In Figure 8(g), for casting at $700^{\circ} \mathrm{C}$ with $3 \% \mathrm{MgFeSi}$, the microstructure revealed the presence of undissolved $\mathrm{MgFeSi}$ (black portions) locked up in the matrices of the cast $\mathrm{Al}$ alloy (white segments). That was not observed at 750 and $800^{\circ} \mathrm{C}$ in Figures $8(\mathrm{~h})$ and $8(\mathrm{i})$. This structure looks similar to a "bull eye" structure obtained previously from the addition of $\mathrm{MgFeSi}$ to cast iron by Alasoluyi et al. [3]. Figure 10 presents the microstructure of cast Al alloy with $\mathrm{MgFeSi}$. The 


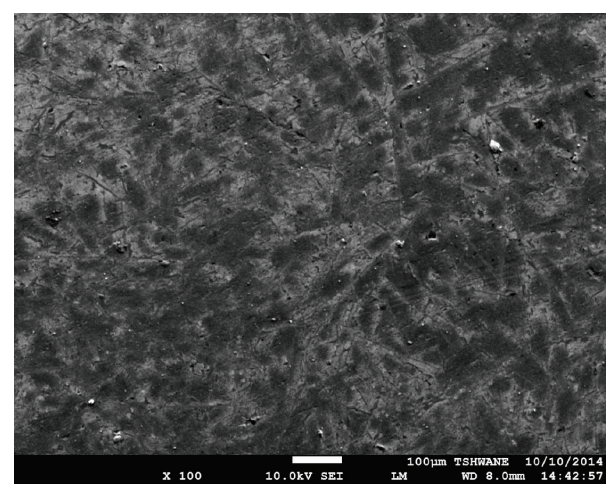

FIGURE 9: SEM electron image showing the microstructure of cast $\mathrm{Al}$ alloy (without inoculant).

examination of the EDX data (Table 2) revealed the effect of the $\mathrm{MgFeSi}$ on the microstructure (the grains).

By combining the EDX data (Table 2) and XRD results (Table 3), it can be inferred that copper $(\mathrm{Cu})$ among the alloying elements singularly has the greatest impact on the strength and hardness of cast aluminium alloys. In the present work, $\mathrm{Al}_{2} \mathrm{CuMg}, \mathrm{AlCu}$, and $\mathrm{CuAl}_{2}$ structures are identified and diffracted in the cast sample by XRD analysis. A substantial amount of $\mathrm{Cu}(1.21 \sim 2.86 \% \mathrm{wt})$ was revealed in the EDX data for all samples (Table 2). It is known that copper improves the machinability of the alloys by increasing matrix hardness, making it easier to generate small chips of cuttings and smooth machine finishes on the lathe and mill.

Trace quantities of three major microstructure modifying alloying elements ( $\mathrm{Ti}, \mathrm{Mn}$, and $\mathrm{Cr}$ ) are detected as inherited from the as-received scrap sample in the AAS data (Table 1). With titanium (Ti) present in the alloy, it forms $\mathrm{TiAl}_{3}$ and refines primary aluminium grains or nucleates primary aluminium dendrites [24]. Szajnar and Wróbel [8] had established that the rise in size decrease of $\mathrm{Al}$ after inoculation with $(\mathrm{Ti}+\mathrm{B})$ results from the $\mathrm{Ti}_{3} \mathrm{Al}$ and $\mathrm{CuTi}_{2}$ to heterogeneous nucleation formation. This is because $\mathrm{Ti}_{3} \mathrm{Al}$ and $\mathrm{CuTi}_{2}$ compounds are the foundation for heterogeneous nucleation and powerfully affect size reduction enhancement in aluminium structure. When nucleation is more frequent, a large number of smaller grains (refined grains) is often obtained as seen in Figures 8(a)-8(h).

At temperature as high as $750^{\circ} \mathrm{C}$, there are subsequent structural changes occurring when aluminium alloy forms an amalgam with $\mathrm{Mn}$ and/or $\mathrm{Cr}$ (Table 1). Report shows that $\mathrm{Al}$ alloy combined with $\mathrm{Mn}$ and/or Cr. That changes the customary platelet structured morphology to the $\mathrm{Al}_{15}(\mathrm{MnFe})_{3} \mathrm{Si}_{2}$ cubic phase (Figure 6(e)) from the iron-rich $\mathrm{Al}_{5} \mathrm{FeSi}$ phase (Figure 6(f)). The obtainable size and amount of the $\mathrm{Al}_{15}(\mathrm{MnFe})_{3} \mathrm{Si}_{2}$ cubic phase have been reported to be a function of the concentration levels and solidification rate $[9,14]$.

Iron $(\mathrm{Fe})$ is present in most traditional casting alloys as a very useful impurity. The supersaturated molten alloy can dissolve the relatively unprotected and exposed tool steel while the molten alloy is in close contact. MgFeSi inoculation supplies $\mathrm{Fe}$ and $\mathrm{Si}$, which combines with aluminium and other elements to form a mixture of hard, insoluble complex phases and is shown in Figures 6(b)-6(f). The $\mathrm{Al}_{5} \mathrm{FeSi}$ phase forms very thin platelets in the form of broom-like structures (Figures 7-10(b)).

In the present study, some of the specimens are cast at varying temperature $750 \pm 50^{\circ} \mathrm{C}$ using moderately high moulding sand permeability [25]. Pouring an aluminium alloy at a temperature above $700^{\circ} \mathrm{C}$ often gives improved metallurgical properties such as strength, hardness, porosity, and microstructure [9-11, 13]. The option of a pouring temperature at $750 \pm 10^{\circ} \mathrm{C}$ is to moderate the gas content in the molten aluminium alloy and to obtain eutectic structure of cast alloy [25]. If the temperature of molten metal (especially for molten aluminium) is higher, the gas content increases, thus increasing the cast porosity if not properly managed by degassing methods.

The micrographs of the scrap alloy and cast aluminium alloy poured at $750^{\circ} \mathrm{C}$ are presented in Figures $6(\mathrm{a})-6(\mathrm{f})$ and $7(\mathrm{a})-7(\mathrm{c})$. The images in Figures $7(\mathrm{a}), 7(\mathrm{~b})$, and $7(\mathrm{c})$ were observed at $\times 800, \times 400$, and $\times 200$ magnifications. The microstructures of the cast $\mathrm{Al}$ alloy with $3 \% \mathrm{MgFeSi}$ appear with nucleation of larger number of small grains. The differences and similarities between the structures and grain sizes of scrap alloy and cast samples are compared in the study. This is with respect to the pouring temperature and $\mathrm{MgFeSi}$ inoculation. The as-received scrap alloy has more coarse grains (Figure 6(a)) than the cast samples (Figure $7(\mathrm{c})$ ). Microstructures of as-received scrap alloy and cast samples are examined under higher resolution metallurgical microscope with a digital camera. An optical micrograph of the binary Al-Si alloy is shown in Figures 6(b)-6(d). The dark areas of the Al-Si eutectic and brighter areas of $\mathrm{Al}$ are observed with the eutectic Si. This possesses very fine transitional Al-Si eutectic according to the American Foundry Society (AFS) modification rating system $[11,26]$.

The microstructural details show different phases resulting from the increase in content of $\mathrm{Si}, \mathrm{Mg}$, and $\mathrm{Cu}$. Aluminium is lost to dross at high temperatures above $670^{\circ} \mathrm{C}$ (being understood from the dross theory), with consequent Fe pickup from the melting pot and cleaning tools, thus adding more to Fe content already present in the commercial alloy sourced from the as-received piston.

In the present work, adding $\mathrm{MgFeSi}$ inoculant to the molten $\mathrm{Al}$ forms different phases with enhanced properties. The aluminium alloy consists of $\mathrm{Al}_{2} \mathrm{Si}_{4} \mathrm{O}_{10}, \mathrm{Al}_{15}(\mathrm{MnFe})_{3} \mathrm{Si}_{2}$, $\mathrm{Al}_{2} \mathrm{CuMg}$, and $\mathrm{Al}_{5} \mathrm{FeSi}$ phases in eutectic $\mathrm{Al}-\mathrm{Si}$ structures. $\mathrm{Si}$ combines with $\mathrm{Mg}$ to form $\mathrm{Mg}_{2} \mathrm{Si}$, which is soluble in the solid alloy. When combined with copper, it forms the precipitationhardening phase, $\mathrm{Al}_{2} \mathrm{CuMg}$ [21], and some other compounds like $\mathrm{AlCu}$ and $\mathrm{CuAl}_{2}$. Subsequently, giving the cast alloy higher hardness and strength, thus these influenced the higher wear resistance value than the as-received scrap alloy.

Furthermore, the removal of oxide inclusions is one of the main challenges of recycling aluminium alloy scrap. At high temperatures 750 and $920^{\circ} \mathrm{C}, \gamma-\mathrm{Al}_{2} \mathrm{O}_{3}$ platelets and $\alpha-\mathrm{Al}_{2} \mathrm{O}_{3}$ particles are, respectively, formed in molten commercially pure $\mathrm{Al}[4]$. In the present instance, the oxidation on the surface of $\mathrm{Al}$ alloy melts is inevitable at high temperature due to the high affinity between the oxygen and $\mathrm{Al}$ when exposed 


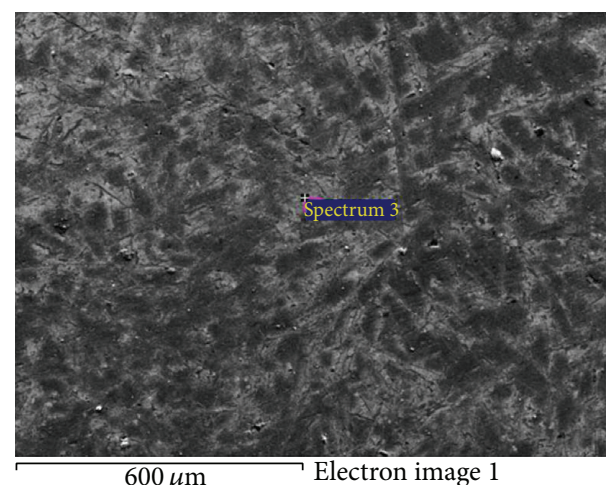

(a)

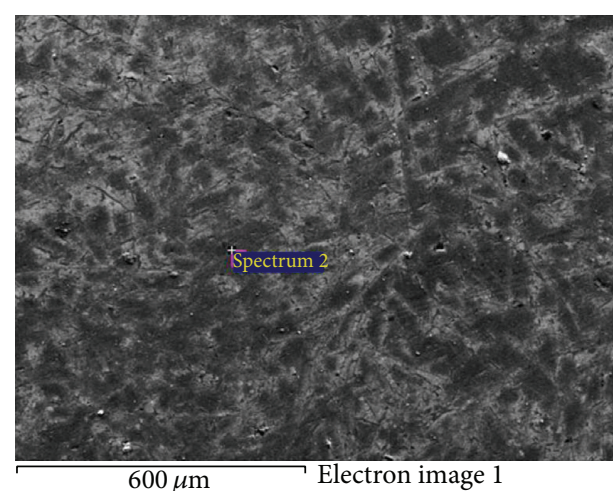

(b)

FIGURE 10: (a) SEM electron image showing target grain of cast Al alloy (with inoculant). (b) SEM electron image showing target grain boundaries of cast $\mathrm{Al}$ alloy (with inoculant).

TABLE 4: XRD analysis for cast Al sample with 3\% MgFeSi.

\begin{tabular}{|c|c|c|c|c|}
\hline Peak & Crystal structures & Phases & Diffraction angle $(2 \theta)$ & Grain size $(\AA)$ \\
\hline 0.20 & Cubic & $\mathrm{Al}_{2} \mathrm{CuMg}$ & 18.4317 & $0.18^{*}$ \\
\hline 0.10 & Cubic & $\mathrm{Al}_{15}(\mathrm{MnFe})_{3} \mathrm{Si}_{2}$ & 20.1235 & $0.15^{*}$ \\
\hline 0.15 & Tetragonal & $\mathrm{MgO} \cdot \mathrm{Al}_{2} \mathrm{O}_{3}$ & 27.3567 & $0.15^{*}$ \\
\hline 0.03 & Triclinic & $\mathrm{Al}_{2} \mathrm{Si}_{4} \mathrm{O}_{10}$ & 29.5332 & $0.05^{*}$ \\
\hline 0.70 & Triclinic & $\mathrm{Al}_{2} \mathrm{Si}_{4} \mathrm{O}_{10}$ & 36.3582 & 0.05 \\
\hline 2.00 & Triclinic & $\mathrm{Al}_{2} \mathrm{Si}_{4} \mathrm{O}_{10}$ & 36.8058 & 0.38 \\
\hline 0.15 & Monoclinic & $\mathrm{AlCu}$ & 38.0476 & $0.10^{*}$ \\
\hline 0.60 & Monoclinic & $\mathrm{SiO}_{2}$ & 39.2411 & 0.60 \\
\hline 0.45 & Triclinic & $\mathrm{Al}_{2} \mathrm{Si}_{4} \mathrm{O}_{10}$ & 43.6492 & 0.34 \\
\hline 0.50 & Cubic & $\mathrm{Al}_{5} \mathrm{FeSi}$ & 47.1035 & $0.29^{*}$ \\
\hline 0.15 & Cubic & $\mathrm{Al}_{5} \mathrm{FeSi}$ & 49.0033 & $0.25^{*}$ \\
\hline 0.35 & Tetragonal & $\mathrm{SiO}_{4}$ & 55.0069 & 0.14 \\
\hline 0.15 & Tetragonal & $\mathrm{Al}_{2} \mathrm{CuMg}$ & 56.3417 & $0.21^{*}$ \\
\hline 0.15 & Tetragonal & $\mathrm{CuAl}_{2}$ & 65.2541 & $0.15^{*}$ \\
\hline 0.15 & Cubic & $\mathrm{Al}_{2} \mathrm{CuMg}$ & 66.7506 & $0.13^{*}$ \\
\hline 0.55 & Hexagonal & $\mathrm{SiO}_{2}$ & 71.1864 & 0.11 \\
\hline
\end{tabular}

* Approximate.

to oxygen containing atmospheres. The various oxides $(\mathrm{MgO}$, $\mathrm{Al}_{2} \mathrm{O}_{3}, \mathrm{SiO}_{2}$, and $\left.\mathrm{Al}_{2} \mathrm{Si}_{4} \mathrm{O}_{10}\right)$ formed at the surface of the melts are easily entrapped in the castings while stirring, skimming, and pouring [27-30]. The intensive "shearing" (resulting from stirring, skimming, and pouring) of the melts prior to solidification breaks up the oxide films and scattered the strong oxide particles within the melt which in turn improved the heterogeneous nucleation and results in the grain refinement. Consequently, there are increases in the hardness and strength of the Al alloy. The grain sizes are calculated from the combination of Bragg's law [31] and Scherrer's equation [32] in

$$
\begin{aligned}
n \lambda & =2 d \sin \theta, \\
\tau & =\frac{0.9 \lambda}{(\beta \cos \theta)},
\end{aligned}
$$

where $d$ is the intergranular spacing, $\lambda$ is the wavelength, and $n$ is the order of reflection of the X-ray.

Additionally, the estimated average grain sizes of the $\mathrm{Al}$ alloy are presented as the approximate values (Table 4), determined from Scherrer's equation in (4).

Whereas 0.9 is the constant shape factor, $\beta$ relates to line amplification at half of the maximum intensity (in radians), and $\theta$ is the Bragg's angle and $\tau$ is the mean (average) size of the ordered crystals.

The diffraction angle $(2 \theta)$ is related to the grain size $D$ by

$$
D=\frac{0.9 \lambda}{\Delta(2 \theta) \cos \theta} \text {. }
$$

The SEM electron and EDX of the Al grains and grain boundaries of the cast $\mathrm{Al}$ alloy with and without MgFeSi inoculant are illustrated in Figures 9-10(b) and Table 2.

Figure 9 presents electron image of the cast Al alloy (without inoculant). The targeted area contains $1.65 \% \mathrm{Mg}$, 


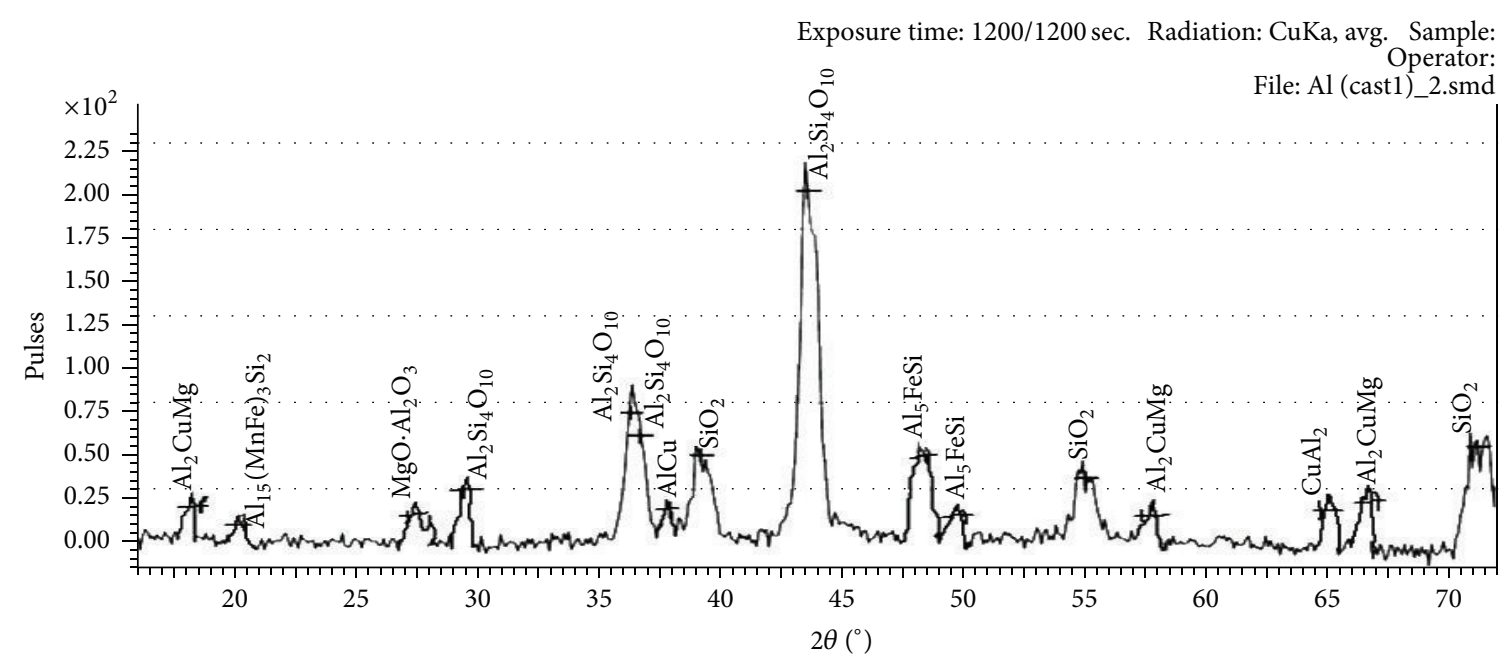

FIGURE 11: The XRD diffractograms of cast aluminium alloy sample with 3\% MgFeSi.

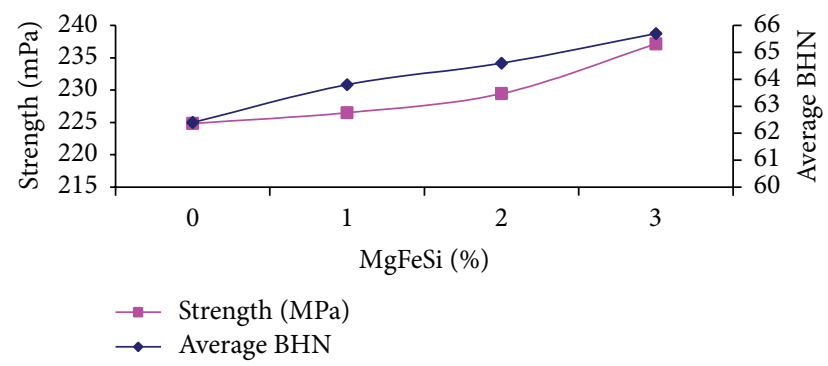

FIGURE 12: Effect of \% MgFeSi increase on mechanical strength and hardness of the cast Al alloy.

1.43\% Fe, 1.31\% Si, $1.04 \% \mathrm{Zn}, 1.21 \% \mathrm{Cu}$, and $78.27 \% \mathrm{Al}$ as revealed in the EDX spectra data (Table 2). In Figure 10, the SEM image of the cast Al alloy (with inoculant) is illustrated. The $600 \mu \mathrm{m}$ size area contains by weight $2.36 \% \mathrm{Mg}, 3.51 \% \mathrm{Fe}$, $2.25 \% \mathrm{Si}, 78.11 \% \mathrm{Al}, 1.85 \% \mathrm{Zn}, 2.86 \% \mathrm{Cu}$, and $1.16 \% \mathrm{Mn}$ as obtained in EDX characterization data (Table 2). Figure 10(b) shows the SEM image of grain boundaries of cast $\mathrm{Al}$ alloy (with inoculant). The $600 \mu \mathrm{m}$ size area contains $72.23 \% \mathrm{Al}$, $3.39 \% \mathrm{Si}, 2.43 \% \mathrm{Mg}, 1.34 \% \mathrm{Cu}, 4.27 \% \mathrm{Fe}$, and $1.71 \% \mathrm{Zn}$ as revealed in EDX studies (Table 2). The results obviously show that the alloy is rich in $\mathrm{Si}$ and $\mathrm{Mg}$. The amount of Si present in the molten metal falls within the standard acceptable limit and thus is suitable enough to enhance the flowability, castability, phase transformation, refined sizes (Table 4 and Figure 11), mechanical strength (Figure 12), and the microstructures.

The differences in the mechanical properties of asreceived scrap and cast samples (with and without inoculant) are reflected in the results tests obtained in combining Tables 1-4 and Figures 11-12. The present results give better insight to understanding the performance and the differences in the wear properties of the as-received scrap and cast test samples previously reported by Ajibola et al. [13, 14, 19, 33]. At large, refined grains and higher values of $\mathrm{BHN}$ and strength were obtained as the $\% \mathrm{MgFeSi}$ was increased from 1 to $3 \%$.

\section{Conclusions}

Aluminium alloy specimen was produced by sand casting. The addition of $\mathrm{MgFeSi}$ produced enhanced properties in the aluminium alloy consisting of $\mathrm{Al}_{2} \mathrm{Si}_{4} \mathrm{O}_{10}, \mathrm{Al}_{15}(\mathrm{MnFe})_{3} \mathrm{Si}_{2}$, $\mathrm{Al}_{2} \mathrm{CuMg}, \mathrm{Al}_{5} \mathrm{FeSi}$, and phases in eutectic $\mathrm{Al}-\mathrm{Si}$ structures, thus giving the cast alloy higher hardness value than the asreceived scrap alloy.

Nevertheless, the addition of MgFeSi changes in the chemical composition and influenced both the mechanical (hardness, strength, and wear resistance) and metallurgical properties (microstructures) of the cast alloy. The increased amount of $\mathrm{MgFeSi}$ from 1 to $3 \%$ enhanced the wear resistance of the cast piston in the brake oil. The grains were more refined as better strength. Inoculating the melt with $\mathrm{MgFeSi}$ forms insoluble compound particles, thus helping to increase the rate of nucleation.

\section{Conflict of Interests}

The authors declare that there is no conflict of interests regarding the publication of this paper.

\section{Acknowledgments}

The authors acknowledge the staff and management of the Premier Wings Engineering Services and Ado-Ekiti for providing the workshop services for the production and preparation of materials used for the study. The SEM/EDX analysis was performed at the Electrochemical \& Materials Characterization Research Laboratory of the Tshwane University of Technology, Pretoria, South Africa, and is hereby appreciated by the authors. 


\section{References}

[1] O. O. Ajibola and B. O. Jimoh, "Aluminium recycling industries in Nigeria: entrepreneurship challenges and opportunities," in Proceedings of the 7th Engineering Forum, vol. 2, pp. 238-247, November 2011.

[2] 2014, https://en.wikipedia.org/wiki/Ferrosilicon.

[3] J. O. Alasoluyi, J. A. Omotoyinbo, J. O. Borode, S. O. O. Olusunle, and O. O. Adewoye, "Influence of secondary introduction of carbon and ferrosilicon on the microstructure of rotary furnace produced ductile iron," International Journal of Science and Technology, vol. 2, no. 2, pp. 211-217, 2013.

[4] Y. Wang, H. T. Li, and Z. Fan, "Oxidation of aluminium alloy melts and inoculation by oxide particles," Transactions of the Indian Institute of Metals, vol. 65, no. 6, pp. 653-661, 2012.

[5] J. Szajnar, M. Stawarz, and T. Wróbel, "Inoculation of pure aluminium structure with $\mathrm{Ti}+\mathrm{B}$ addition in impulse magnetic field," Journal of Achievements in Materials and Manufacturing Engineering, vol. 14, pp. 64-69, 2006.

[6] J. Szajnar and T. Wróbel, "Influence of magnetic field and inoculation on columnar structure transformation," Journal of Achievements in Materials and Manufacturing Engineering, vol. 17, no. 1-2, pp. 209-212, 2006.

[7] J. Szajnar and T. Wróbel, "Inoculation of primary structure of pure aluminium," Journal of Achievements in Materials and Manufacturing Engineering, vol. 20, no. 1-2, pp. 283-286, 2007.

[8] J. Szajnar and T. Wróbel, "Inoculation of aluminium with titanium and boron addition," Journal of Achievements in Materials and Manufacturing Engineering, vol. 23, no. 1, pp. 51-54, 2007.

[9] D. Apelian, "Aluminium cast alloy: enabling tools for improved performance," Worldwide Report 2009, North American DieCasting Association (NADA), Arlington Heights, Ill, USA, 2009.

[10] S. Mahipal, B. Manjinder, S. Rohit, and A. Hitesh, "Behaviour of aluminium alloy casting with the variation of pouring temperature and permeability of sand," International Journal of Scientific \& Engineering Research, vol. 4, no. 6, pp. 1497-1502, 201.

[11] J. E. Gruzleski and B. M. Closset, The Treatment of Liquid Aluminium-Silicon Alloys, AFS, Des Plaines, Ill, USA, 1st edition, 1990.

[12] S. Das, S. V. Prasad, and T. R. Ramachandran, "Microstructure and wear of cast (Al-Si alloy)-graphite composites," Wear, vol. 133, no. 1, pp. 173-187, 1989.

[13] O. O. Ajibola, B. O. Adewuyi, and D. T. Oloruntoba, "Wear behaviour of sand cast eutectic Al-Si alloy in hydraulic brake fluid," International Journal of Innovation and Applied Studies, vol. 6, no. 3, pp. 420-430, 2014.

[14] O. O. Ajibola, D. T. Oloruntoba, and B. O. Adewuyi, "Metallurgical study of cast aluminium alloy used in hydraulic master brake calliper," International Journal of Innovation and Scientific Research, vol. 8, no. 2, pp. 324-333, 2014.

[15] ASM International, "Casting," in Metals Handbook, vol. 15 of The ASM Handbook, ASM International, Geauga County, Ohio, USA, 9th edition, 1992.

[16] American Foundrymen's Society, Aluminum Casting Technology, American Foundrymen's Society, 1986.

[17] T. B. Massalski, Binary Alloy Phase Diagrams, vol. 1-2, ASM International, Geauga County, Ohio, USA, 1986.

[18] O. O. Ajibola, B. O. Adewuyi, and D. T. Oloruntoba, "Design and performance evaluation of wear test jig for alumium alloy substrate in hydraulic fluid," in Proceedings of the 8th Engineering Forum, vol. 1, pp. 85-96, Ado Ekiti, Nigeria, October 2012.

[19] O. O. Ajibola, D. T. Oloruntoba, and B. O. Adewuyi, "Design and performance evaluation of wear test jig for aluminium alloy substrate in hydraulic fluid," in Proceedings of the Inaugural African Corrosion Congress and Exhibition (AfriCORR '14), Pretoria, South Africa, July 2014.

[20] ASM International, Friction, Lubrication, and Wear Technology, vol. 18, ASM International, Geauga County, Ohio, USA, 1992.

[21] T. H. Ludwig, P. L. Schaffer, and L. Arnberg, "Influence of some trace elements on solidification path and microstructure of $\mathrm{Al}$ Si foundry alloys," Metallurgical and Materials Transactions A, vol. 44, no. 8, pp. 3783-3796, 2013.

[22] O. O. Ajibola, D. T. Oloruntoba, and B. O. Adewuyi, "Effect of hard surface grinding and activation on electroless-nickel plating on cast aluminium alloy substrates," Journal of Coatings, vol. 2014, Article ID 841619, 10 pages, 2014.

[23] G. Y. Liu, Effect of ageing heat treatment on the hardness and tensile properties of aluminum A356.2 casting alloy [M.S. thesis], McMaster University, 2009, Paper 4404, http://digitalcommons.mcmaster.ca/opendissertations/4404.

[24] H. Yilmazer, M. Niinomi, K. Cho et al., "Nanostructure of $\beta$-type titanium alloys through severe plastic deformation," Advanced Materials Letters, vol. 5, no. 7, pp. 378-383, 2014.

[25] R. J. Fruehan, "Gases in metals," in Casting, vol. 15, ASM International, Geauga County, Ohio, USA, 9th edition, 1986.

[26] G. K. Sigworth and T. A. Engh, "Chemical and kinetic factors related to hydrogen removal from aluminum," Metallurgical Transactions B, vol. 13, no. 3, pp. 447-460, 1982.

[27] X. Dai, X. Yang, J. Campbell, and J. Wood, "Effects of runner system design on the mechanical strength of Al-7Si-Mg alloy castings," Materials Science and Engineering: A, vol. 354, no. 1-2, pp. 315-325, 2003.

[28] J. Campbell, "An overview of the effects of bifilms on the structure and properties of cast alloys," Metallurgical and Materials Transactions B, vol. 37, no. 6, pp. 857-863, 2006.

[29] X. Cao and J. Campbell, "The nucleation of Fe-Rich phases on oxide films in Al-11.5Si-0.4Mg cast alloys," Metallurgical and Materials Transactions A, vol. 34, no. 7, pp. 1409-1420, 2003.

[30] X. Cao and J. Campbell, “The solidification characteristics of Ferich intermetallics in Al-11.5Si-0.4Mg cast alloys," Metallurgical and Materials Transactions A, vol. 35, no. 5, pp. 1425-1435, 2004.

[31] 2015, https://en.wikipedia.org/wiki/Bragg\%27s_law.

[32] 2015, https://en.wikipedia.org/wiki/Scherrer_equation.

[33] O. O. Ajibola, D. T. Oloruntoba, and B. O. Adewuyi, "Design and performance evaluation of wear test jig for aluminium alloy substrate in hydraulic fluid," African Corrosion Journal, vol. 1, no. 1, pp. 40-45, 2015. 

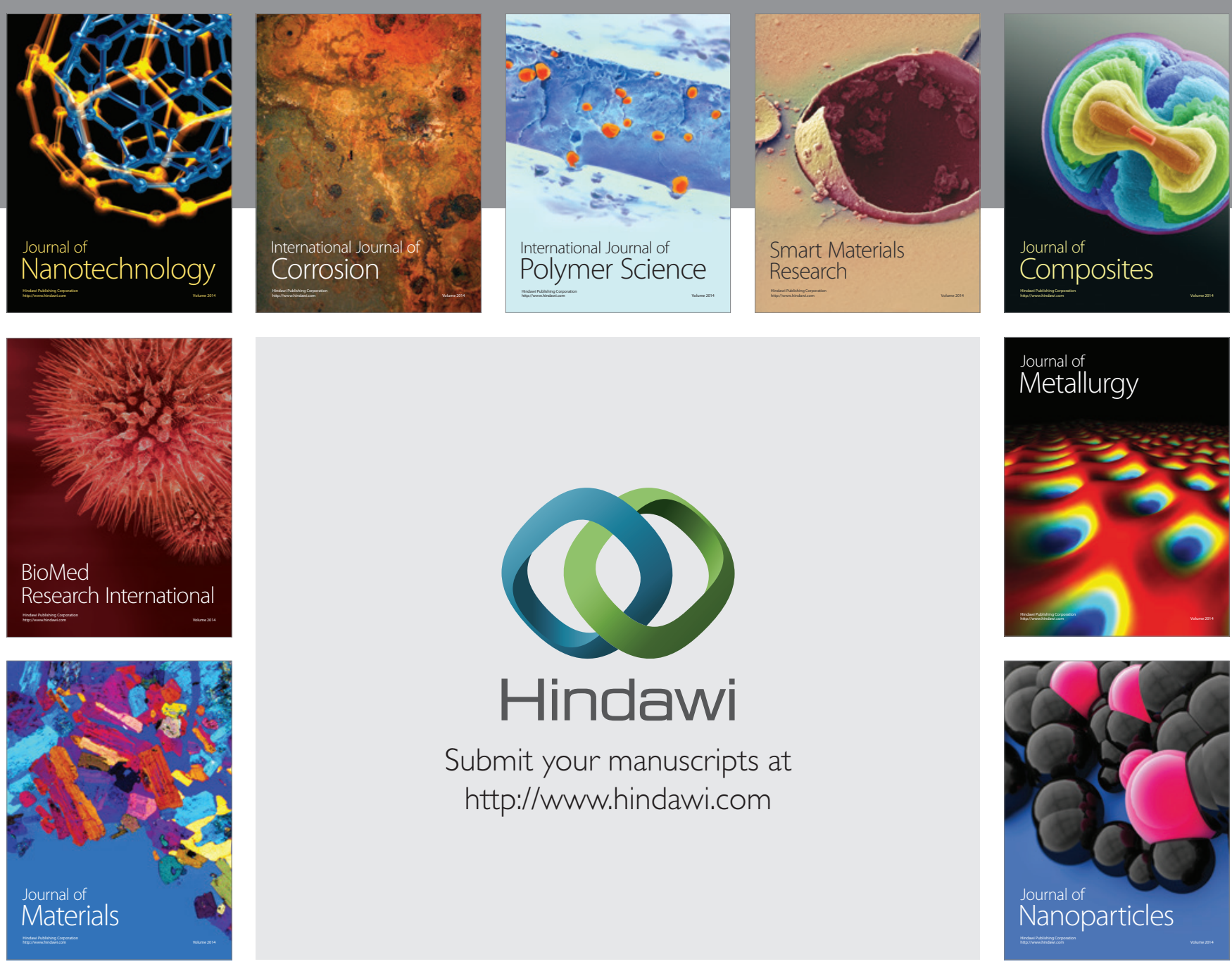

Submit your manuscripts at http://www.hindawi.com
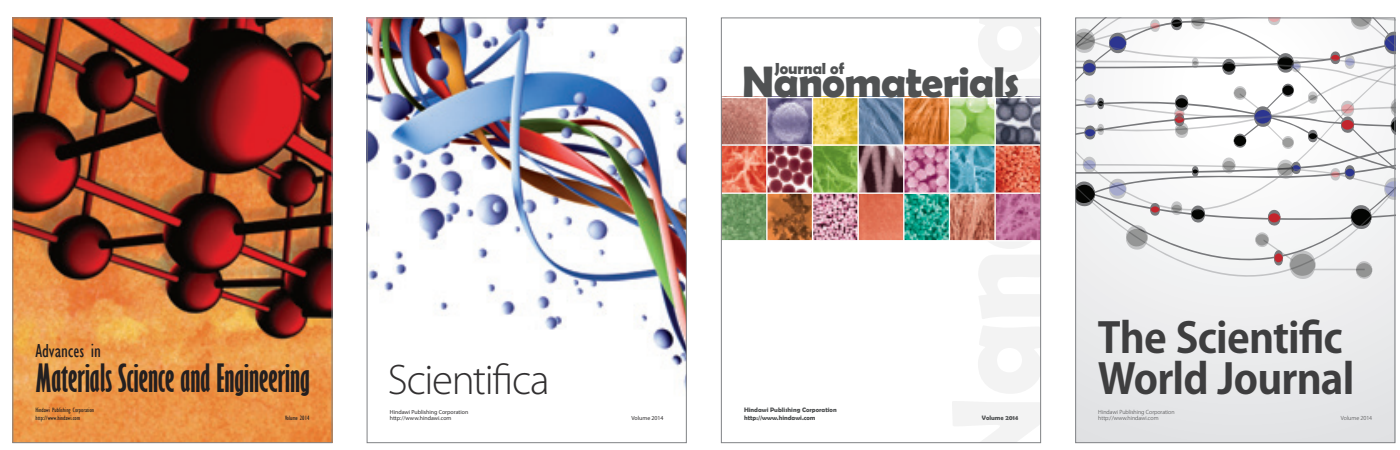

\section{The Scientific World Journal}
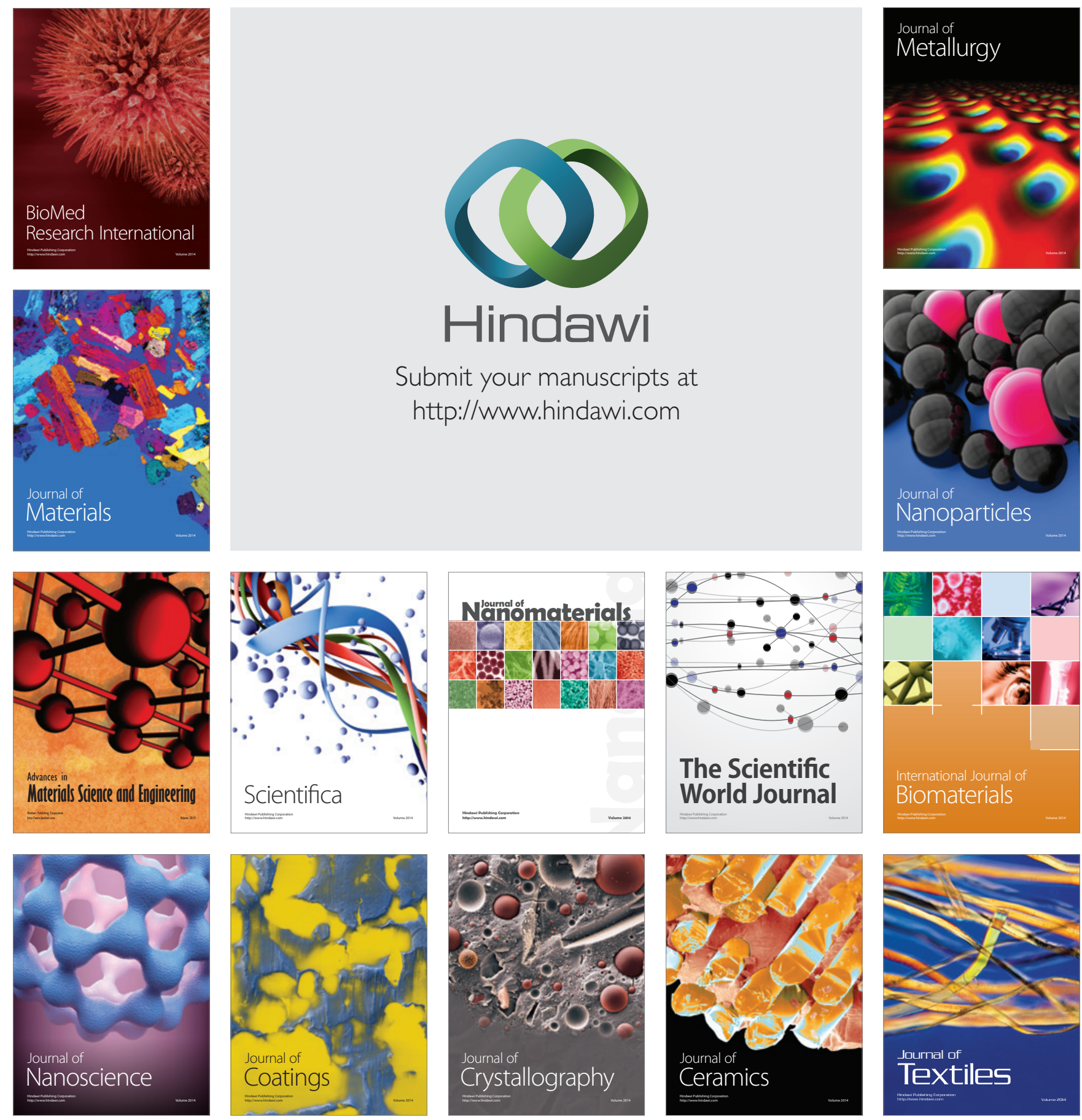